\title{
Hedgehog-regulated localization of Vax2 controls eye development
}

\author{
Jin Woo Kim ${ }^{1}$ and Greg Lemke ${ }^{2}$ \\ Molecular Neurobiology Laboratory, The Salk Institute, La Jolla, California 92037, USA
}

Cell fates in the optic neuroepithelium are determined by the combinational action of homeotic transcription factors. One of these is Vax2, a homeodomain protein that ventralizes the vertebrate eye field by repressing transcription of the Pax6 gene. We find that Vax2 shuttles between the nucleus and cytoplasm as a function of time in eye development, and that this dynamic shuttling is an essential feature of retinal differentiation. We show that subcellular localization of Vax2 is controlled by phosphorylation of a single serine residue, S170, downstream from its homeodomain, and that this modification results in the exclusion of Vax2 from the nucleus. Phosphorylation of $\mathrm{S170}$ is most probably mediated by protein kinase A and is antagonized by the ventralizing morphogen Sonic hedgehog. Expression of a nonphosphorylatable, constitutively nuclear Vax2 protein in the chick optic vesicle results in constitutive repression of Pax6, and leads to the formation of an eyeless embryo. These results indicate that regulated changes in Vax2 localization modify the developmental competence of the optic neuroepithelium over time and thereby provide a mechanism for the sequential staging of eye development.

[Keywords: Pax6; Sonic hedgehog; Vax genes; nuclear translocation; retina]

Supplemental material is available at http://www.genesdev.org.

Received June 23, 2006; revised version accepted August 22, 2006.

The vertebrate eye develops from the optic vesicle, a neuroepithelial evagination of the embryonic brain. Even at this early stage of its development, gradients of morphogens have already patterned the optic primordium along its dorsal-ventral axis (Chow and Lang 2001). Prominent among these morphogens is Sonic hedgehog (Shh), which confers ventral identity. Neuroepithelial cells that are proximal to the midline source of Shh adopt the most ventral optic fate and form the optic nerve, while cells that are further removed from the midline assume a more dorsal identity and form the neural retina proper (Mui et al. 2005).

Transcription factors downstream from Shh delimit these initially specified neuroepithelial segments (Ekker et al. 1995; Macdonald et al. 1995; Ingham and McMahon 2001; Take-uchi et al. 2003). Among the most potent of these regulators are two sets of closely related homeodomain proteins-the "Paired-like" proteins Pax2 and Pax6, and the Emx-related proteins Vax1 (for ventral anterior homeobox) and Vax2. The genes encoding Pax2, Vax1, and Vax2 are each sensitive to induction by Shh, and all three genes act in concert to drive development of

${ }^{1}$ Present address: Department of Biological Sciences, Korea Advanced Institute of Science and Technology, 373-1 Guseong-dong, Yuseong-gu, Daejeon 305-701, South Korea

${ }^{2}$ Corresponding author.

E-MAIL lemke@salk.edu; FAX (858) 455-6138.

Article is online at http://www.genesdev.org/cgi/doi/10.1101/gad.1462706. the optic nerve. In contrast, Pax6 is much less sensitive to Shh regulation and is-from flies to man-a dominant driver of retinal differentiation (Quiring et al. 1994; Halder et al. 1995; Chow et al. 1999).

Recent analyses of mouse and zebrafish mutants indicate that Vax1 and Vax2, which are coexpressed in the optic vesicle, together promote differentiation of the optic nerve by blocking its differentiation into retina (Take-uchi et al. 2003; Mui et al. 2005). They achieve this by repressing transcription of the Pax6 gene, via binding to and inhibiting the activity of a critical retinal enhancer element of this gene-the $\alpha$-enhancer (Mui et al. 2005). In mice that lack both Vax 1 and Vax2, this Pax6 enhancer is aberrantly activated in the presumptive optic nerve, which is thereby transformed in its entirety into additional neural retina (Mui et al. 2005).

Although the activity that Vax2 exhibits as a repressor of the Pax6 gene is clearly critical to optic nerve development, this activity nonetheless poses a conundrum: After the optic vesicle stage, the mouse Vax2 and Pax6 genes are coexpressed in the ventral neural retina. This coexpression occurs during a period of embryogenesisfrom approximately embryonic day 12.5 (E12.5) to birth-in which Pax6 continues to play essential roles in cell fate specification and differentiation for retinal progenitor cells (RPCs). So how can Vax2 and Pax6 be coexpressed in the same cells, if Vax2 indeed represses transcription of the Pax6 gene?

We have found that retinal transcription of Pax6 is 
made possible by the exclusion of the Vax2 protein from the nuclei of developing retinal cells after approximately E12.5. We find that subcellular localization of the protein is controlled by phosphorylation of Ser 170, which is located just C-terminal to the Vax2 homeodomain. Phosphorylation at this site, which is most probably mediated by protein kinase A (PKA), confines Vax2 to the cytoplasm. We further find that S170 phosphorylation is antagonized by Shh, whose action drives Vax 2 into the nucleus. Finally, we show that forced embryonic expression of a mutant Vax2 protein-which cannot be phosphorylated at S170 and which is constitutively nuclearblocks retinal development in favor of optic nerve development, the converse of the phenotype seen in $\operatorname{Vax}^{-/}$. $V a x 2^{-/-}$double mutants. Together, these results demonstrate that the developmentally regulated intracellular shuttling of Vax 2 provides a mechanism for fine spatial and temporal tuning of its activity, without a change in Vax2 gene expression. This in turn allows the same transcription factor to act sequentially during noncontiguous phases of eye development.

\section{Results}

Dynamic nuclear translocation of Vax2

Genetic studies indicate that Vax2 acts during two distinct windows of mouse eye development: first from E9.5-E11.5, when the developing eye is segregated into domains that will give rise to the optic nerve, neural retina, and retinal pigment epithelium (Mui et al. 2005), and again later in the postnatal retina, to establish its dorsal-ventral polarity (Mui et al. 2002). At E9.5-E11.5, the protein functions as a direct repressor of the Pax6 gene, blocking the development of the ventral optic stalk into neural retina, and thereby diverting its development into optic nerve (Mui et al. 2005). Immunostaining with a Vax2-specific antibody (see Supplementary Fig. 1) reveals that both Vax2 and Pax6 are exclusively nuclear proteins in the presumptive ventral retina at this time (Fig. 1A,C).

However, by E14.5 in the ventral retina proper, Pax6 remains confined to retinal nuclei, where it drives retinal development, but Vax2 is now detected in the cytoplasm of these cells (Fig. 1B,C). The first cells to differentiate in the embryonic retina are retinal ganglion cell (RGC) neurons, whose axons extend into the developing optic nerve. At E14.5, these RGC axons are filled with Vax2 protein that has been excluded from the nucleus and transported into the developing optic nerve (Fig. 1B). In contrast to Vax2, immunostaining with an antibody specific to Vax1 (Supplementary Fig. 1), which is confined to the more midline-proximal domains of the developing optic cup, reveals that this protein is exclusively nuclear at all stages of optic development (Fig. 1D; Supplementary Fig. 2).

We examined the dynamics of Vax2 localization in the ventral optic cup and ventral retina during embryonic and early postnatal eye development by immunostaining sections for Vax2, counterstaining with DAPI to visual- ize nuclei, and then quantitating the percentage of Vax2-positive cells in which the protein was either exclusively nuclear, exclusively cytoplasmic, or distributed between nucleus and cytoplasm (Fig. 1C; Supplementary Fig. 2). This analysis indicates that exit of Vax2 from the nuclei of ventral retinal cells is underway by E12.5 and is essentially complete by E16.5. The nearly exclusive cytoplasmic localization of Vax2 protein is maintained for the next 2-3 d of embryogenesis (Fig. 1C; Supplementary Fig. 2). Late in embryogenesis and during the first postnatal week, there is then a remobilization of Vax2 back into the nucleus, primarily in RGCs, although nuclear localization during this second window is not as pronounced as at E10.5 (Fig. 1C; Supplementary Fig. 2).

We also examined the localization of the Vax2 and Vax 1 proteins biochemically, by using low speed centrifugation to separate eye, retina, and optic nerve homogenates into crude nuclear and cytoplasmic fractions, and then probing these fractions for Vax1 and Vax2 protein expression by Western blot (Fig. 1D). Vax1 partitioned exclusively to the nuclear fraction throughout development. At E14.5, Vax1 is detectable in neither fraction of retinal lysates, because the $\operatorname{Vax} 1$ gene is exclusively expressed in the optic nerve by this time (Bertuzzi et al. 1999). Vaxl protein reappears in the nuclear fraction of retinal lysates around the day of birth and is readily detected by postnatal day 12 (P12) (Fig. 1D; Supplementary Fig. 2), coincident with the previously described appearance of retinal astrocytes. These Vaxlpositive astrocytes migrate in from the optic nerve beginning around the day of birth (Watanabe and Raff 1988). In contrast to the exclusively nuclear localization of Vax1 throughout development, Vax2 is exclusive to the nuclear fraction only at E10.5, and is seen to be equally distributed between the nuclear and cytoplasmic fractions of eye lysates by E12.5. Vax2 is biased toward the cytoplasmic fraction of E14.5 retinal homogenates and is almost exclusively confined to this fraction by E16.5 (Fig. 1D). Vax2 reappears in the nuclear fraction of retinal lysates prepared on the day of birth (P0 in Fig. 1D). This diminishes over the first postnatal week, such that by $\mathrm{P} 12$, the Vax2 distribution is again strongly biased toward the cytoplasm (Fig. 1D). The distributions of the Vax1 and Vax2 proteins in homogenates prepared from the P12 optic nerve are particularly informative (Fig. 1D). The nuclear Vaxl protein in these lysates is derived from the Vax1-positive (Pax6-negative) astrocytes of the nerve. In contrast, the cytoplasmic Vax2 protein of the P12 optic nerve is not produced by the cells of the nerve, but rather by the RGCs of the retina, whose Vax2-positive axons (Fig. 1B, left panel) project through the nerve and into the brain.

\section{A small region $C$-terminal to the homeodomain controls Vax2 localization}

In order to delimit domains of the Vax 2 protein that are responsible for its dynamic shuttling during development, a series of Vax2 deletion constructs fused to green 
A

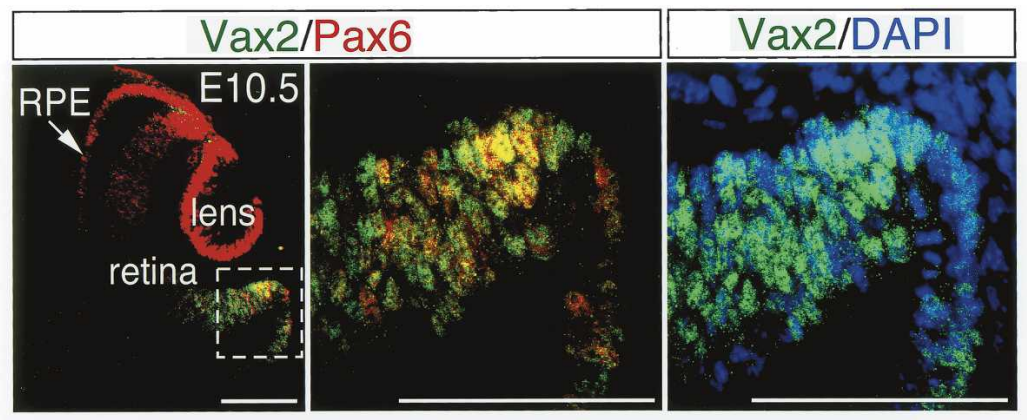

B

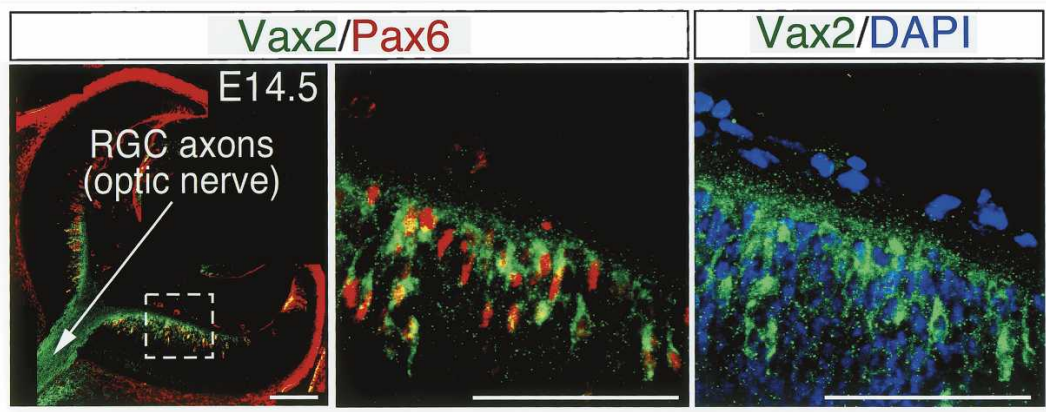

C

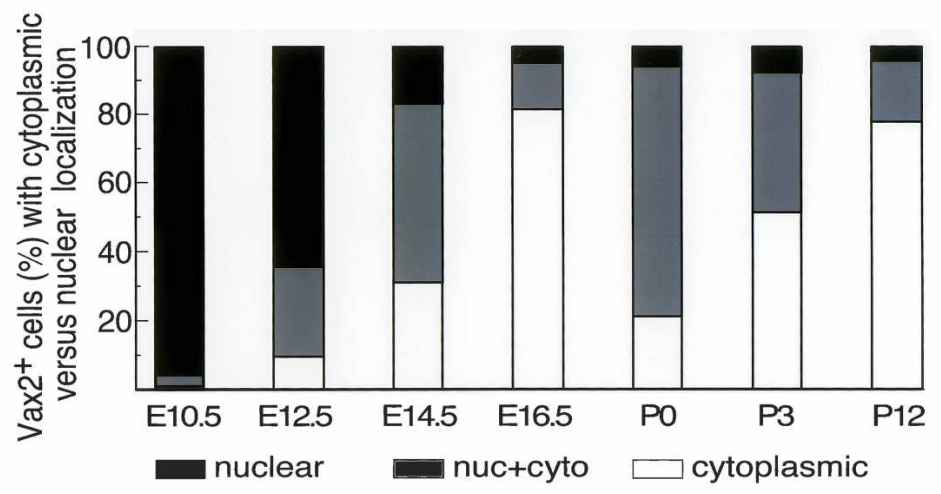

D

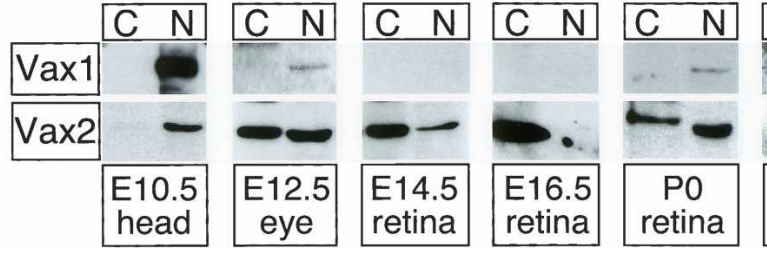

fluorescent protein (GFP) were analyzed for their subcellullar localization following transfection into cultured Schwann cells (Fig. 2A), which express endogenous Vax2 (Bertuzzi et al. 1999). Under the culture conditions we employed (see Materials and Methods), full-length Vax2 is distributed between the nucleus and the cytoplasm, whereas the Vax2 homeodomain alone, which contains a well-conserved nuclear localization signal near its $\mathrm{C}$ terminus, is localized exclusively to the nucleus (Fig. 2A). Comparison of the nuclear versus cytoplasmic expression of the N3/N4 and M2/M3 fusion proteins diagrammed in Figure 2A narrowed the Vax2 cytoplasmic localization signal to the Vax-divergent domain 2 (VD2) (Fig. 2A, red segment), a 21-residue region immediately $\mathrm{C}$-terminal to the homeodomain.
Figure 1. Dynamic nuclear-cytoplasmic translocation of Vax2 during retinal development. $(A, B)$ Ten-micrometer sections of E10.5 $(A)$ and E14.5 $(B)$ embryonic mouse eyes costained with a rabbit polyclonal Vax2 antibody (green) and a mouse monoclonal Pax6 antibody (red). Vax2 and Pax6 are coexpressed in the E10.5 ventral optic cup $(A)$ and E14.5 ventral retina $(B)$. Both proteins are localized to nuclei at E10.5, whereas Vax2 is prominent in the cytoplasm and axons of RGCs at E14.5 (shown in $B)$. Left and middle panels of $A$ and $B$ are Vax2/Pax6 coimmunostaining, with the middle panels corresponding to enlarged images of the boxed area in the left panels. Right panels are equivalent to the middle panels, and illustrate Vax2 immunostaining together with DAPI staining (blue) to visualize nuclei. Bars, $100 \mu \mathrm{m} .(C)$ Quantitation of the fraction of $\mathrm{Vax}^{+}$retinal cells displaying nuclear versus cytoplasmic localization of the protein, as a function of time in development. Confocal images of Vax2 immunostaining from retinal sections were counted for cells expressing Vax2 exclusively in the cytoplasm (open bars), in both the nucleus and the cytoplasm (gray bars), or exclusively in the nucleus (black bars). Numbers of cells in each category were divided by the total Vax2 ${ }^{+}$cells counted to obtain the percentage values displayed in the graph. Values are the mean from five sections $(>200$ total cells counted per section). (D) Homogenates of the indicated tissues were separated into nuclear and cytoplasmic fractions (see Materials and Methods) and monitored for Vax1 or Vax2 protein expression by Western blot with anti-Vax1 or anti-Vax2 antibodies.

Given that Vax 1 is always a nuclear protein, while Vax2 is not, we also generated a series of Myc-tagged Vax1/Vax2 domain-swap hybrids and then analyzed the subcellular distribution of these hybrids following transfection into cultured Schwann cells (Fig. 2B). We monitored nuclear versus cytoplasmic expression both microscopically, through immunostaining for Myc, and biochemically, by analyzing crude nuclear versus cytoplasmic fractions of transfected cells by Western blot. By both methods, a protein identical to Vax1-except for the presence of the Vax2 VD2 domain-was strongly biased toward expression in the cytoplasm. In contrast, a protein identical to Vax2-except for the presence of the Vax1 VD2 domain-was strongly biased toward expression in the nucleus (Fig. 2B). 
Kim and Lemke

A
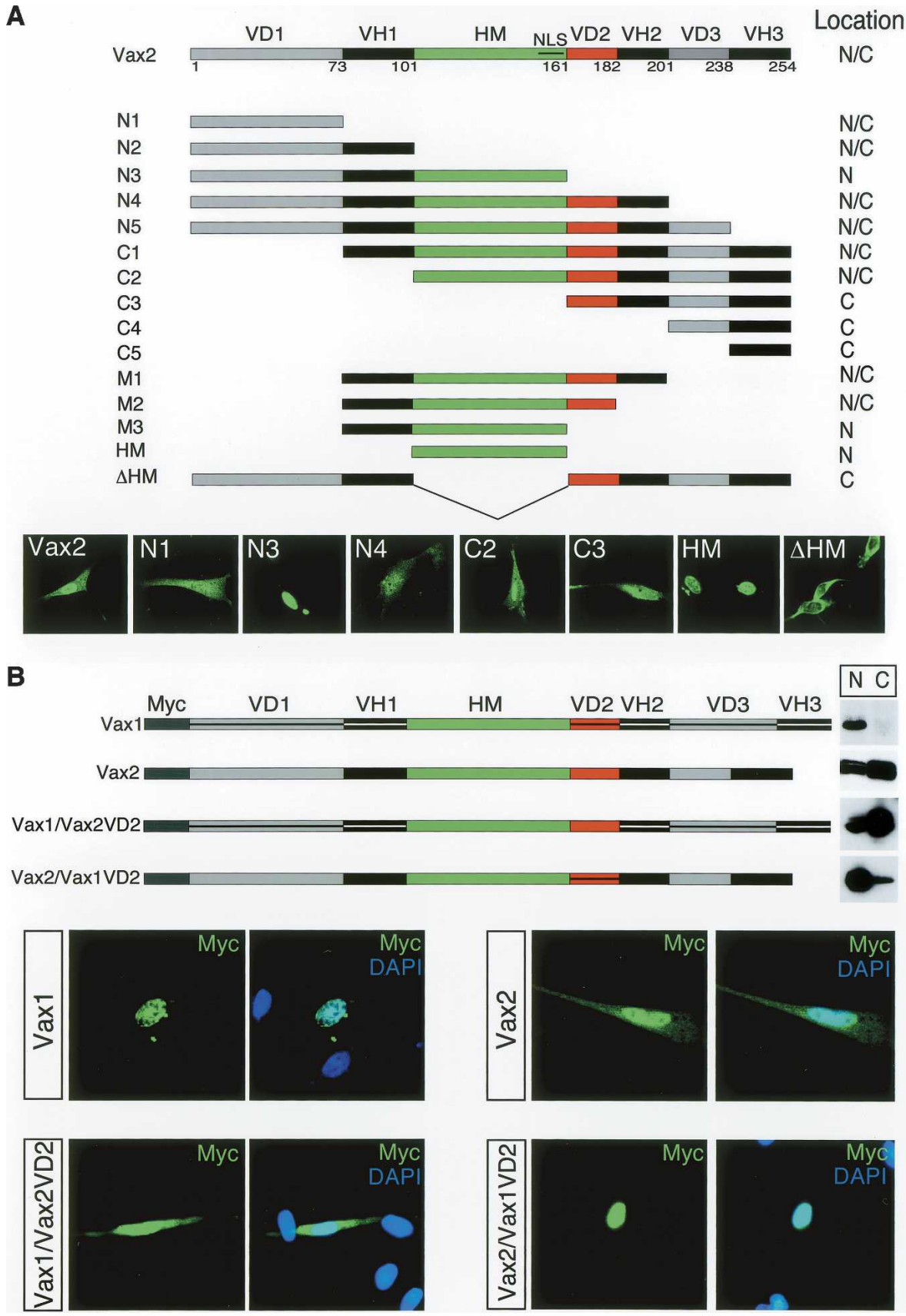

Figure 2. Identification of the critical domain for Vax2 cytoplasmic localization. (A) Subcellular localization of Vax2 deletion mutant proteins. The diagrammed panel shows Vax2 deletion mutants (N1, N2, etc.) were fused to GFP and expressed in cultured Schwann cells. Transfected cells were then monitored for cytoplasmic $(\mathrm{C})$, nuclear + cytoplasmic $(\mathrm{N} / \mathrm{C})$, or nuclear $(\mathrm{N})$ localization of the indicated GFP fusion proteins. Selected examples of differential localization for wild-type Vax2 and for the N1, N3, N4, C2, C3, HM, and $\triangle \mathrm{HM}$ deletion constructs are displayed in the GFP images below the construct diagrams. (VH) Vax homologous domain; (VD) Vax divergent domain; (HM) homeodomain; (NLS) nuclear localization signal in the HM. (B) VD2-dependent cytoplasmic retention of Vax2. Myc-tagged chimeric proteins of Vax1 containing the Vax2 VD2 [Vax1/Vax2(VD2)], or of Vax2 containing the Vax1 VD2 [Vax2/Vax1(VD2)], were expressed in Schwann cells, and their subcellular localization was monitored by immunostaining with a mouse anti-Myc monoclonal antibody (green), together with DAPI (nuclear) counterstaining (blue). Vax1 and Vax2/Vax1(VD2) are nuclear proteins (upper left and lower right set of immunofluorescence images, respectively), whereas Vax2 and Vax1/Vax2(VD2) are distributed between the nucleus and cytoplasm (upper right and lower left set of panels, respectively). Nuclear (N) versus cytoplasmic (C) localization was also monitored by Western blot of pellet (N) and supernatant (C) fractions of low-speed centrifugations of cell culture homogenates, as for the blots in Figure 1D. 
PKA phosphorylates serine residues in the Vax2 VD2 domain

When immunoblotted following expression in cultured cells, both Vax2 and the Vax1-Vax2(VD2) hybrid protein migrate as a cluster of multiple closely spaced bands on SDS-PAGE, whereas Vax1 and Vax2-Vax1(VD2) migrate as a single band (Fig. 3; Supplementary Fig. 1). The multiple Vax2 bands are due to phosphorylation: Treatment of immunoprecipitated Vax2 with $\lambda$ protein phosphatase ( $\lambda$ PPase) results in the disappearance of the higher molecular weight bands of the cluster (Fig. 3B).

Sequence alignment of the Vax1 and Vax2 VD2 regions from multiple species highlighted a serine-rich segment (SRS) with several potential phosphorylation sites (NetPhos site search at http://www.cbs.dtu.dk/services/ NetPhos) within VD2 (Fig. 3A). The presence of A169 and $\mathrm{S} 170$ in mouse and human Vax2 generates potential phosphorylation sites that are not present in Vax1. S170 and S171 in mouse Vax2 are potential sites for PKA, S172 is a potential site for casein kinase II (CKII), and S170 is also a potential site for glycogen synthase kinase $\alpha$ and $\beta$ $(\mathrm{GSK} \alpha / \beta)$ following a priming phosphorylation at S174. The importance of the SRS is highlighted by our finding that a Vax2 deletion mutant lacking only S170 to S174 (Vax2-ASSSAS) is exclusively nuclear when expressed in cultured Schwann cells, and that this protein migrates as a single band on SDS-PAGE (Fig. 3C). We therefore examined the phosphorylation of residues within the SRS in vitro (Supplementary Fig. 3). A Vax2-GST (glutathi-
one-S-transferase) fusion protein expressed in Escherichia coli was phosphorylated by both PKA and CKII in vitro (Supplementary Fig. 3A). PKA-mediated phosphorylation of Vax2 generated a doublet on SDS-PAGE, implying the existence of at least two phosphorylation sites. We assessed phosphorylation within the SRS by individually mutating its serine residues to alanine $(\mathrm{S} \rightarrow \mathrm{A})$, in the context of the GST-Vax2(VD2-VH2) protein (Supplementary Fig. 3B). Mutation of Ser 170 to alanine (S170A) reduced phosphorylation by PKA, whereas the same mutation at Ser 171 (S171A) did not. Mutation of both S170 and S171 to alanine completely abolished phosphorylation by PKA, whereas mutation of the potential CKII site at S172 only modestly reduced phosphorylation.

\section{The phosphorylation status of $S 170$ determines Vax2 localization}

Given the above results, we carried out an exhaustive mutational analysis of the serine residues within the SRS and analyzed the mutants with respect to nuclear versus cytoplasmic localization following transfection into cultured Schwann cells (Fig. 4). An S170A mutation, which precludes PKA phosphorylation at Ser 170, strongly promoted nuclear localization of Vax2 (Fig. 4B), whereas an S170D mutation, which mimics phosphorylation with respect to charge, promoted cytoplasmic expression (Fig. 4C). In contrast, the S171A, S171D, and

A

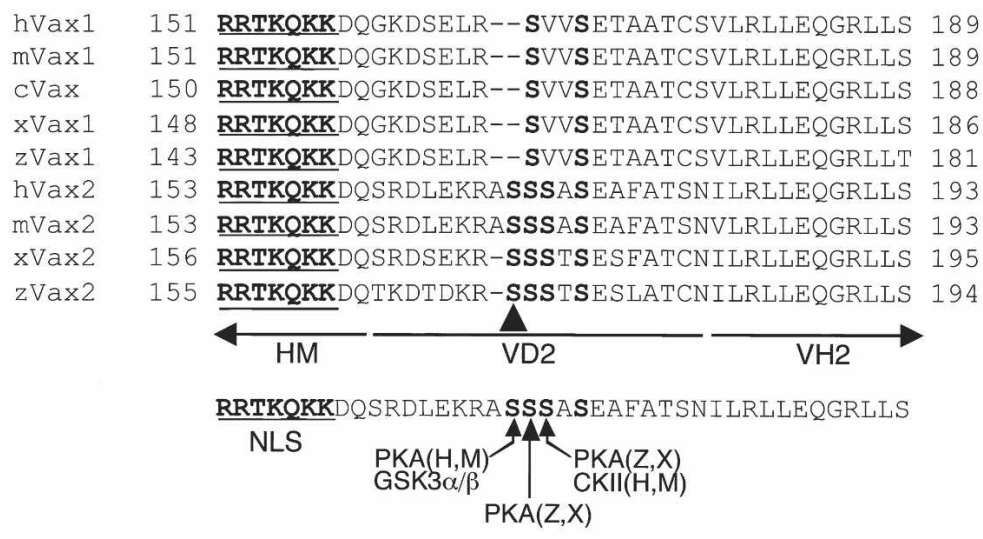

B

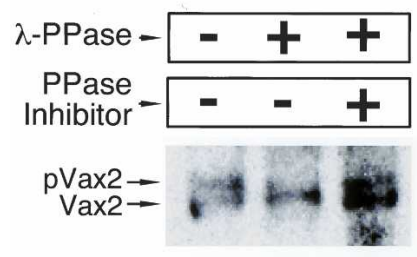

C

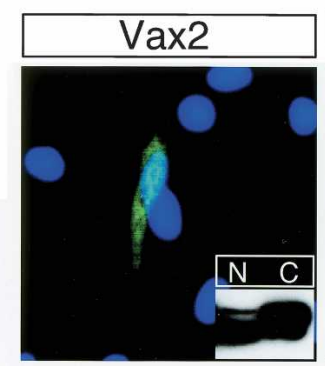

Figure 3. The SRS in VD2 is essential for the cytoplasmic localization of Vax2. $(A)$ Amino acid sequence alignment of the cytoplasmic retention domain (VD2) of various Vax1 and Vax2 proteins. (H) human; (M) mouse; (X) Xenopus; (Z) zebrafish. The Vax2 VD2 carries an SRS that contains potential target sites for phosphorylation by PKA and CKII. The arrowhead marks Ser 170 in mouse Vax2. (B) Vax2 is a phosphoprotein in vivo. Vax2 protein was isolated by immunoprecipitation from Schwann cells, followed by treatment with $\lambda$ protein phosphatase ( $\lambda$-PPase; New England BioLabs; $400 \mathrm{U}$ ) in the presence or absence of the phosphatase inhibitor cocktail 2 (PPase Inhibitor; Sigma), and was analyzed by $10 \%$ SDS-PAGE and Western blotting with antiVax2 antibody. (C) Essential role of SRS in the cytoplasmic retention of Vax2. Myctagged wild-type mouse Vax2 or Vax2 $\triangle$ SSSAS, a deletion mutant lacking amino acids $170-174$ of $\operatorname{mVax} 2$, was expressed in Schwann cells, and its subcellular localization was monitored by immunostaining with anti-Myc antibody (green) and DAPI (blue). Boxed insets are immunoblots with anti-Myc antibody detecting Myc-tagged Vax2 proteins in the cytoplasmic $(\mathrm{C})$ or in the nuclear $(\mathrm{N})$ fractions of the transfected cells, as for Figure 2B. 
Kim and Lemke
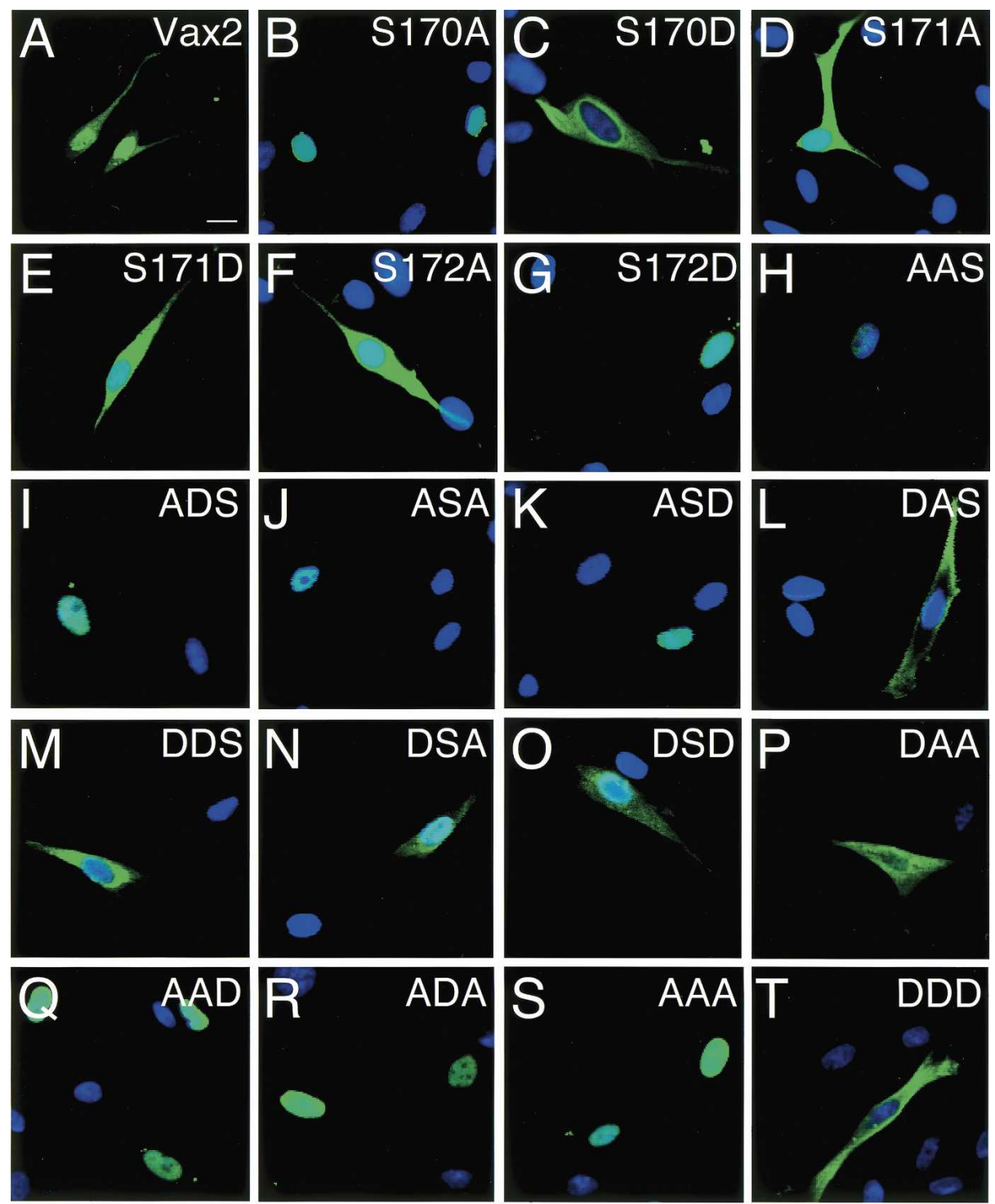

U
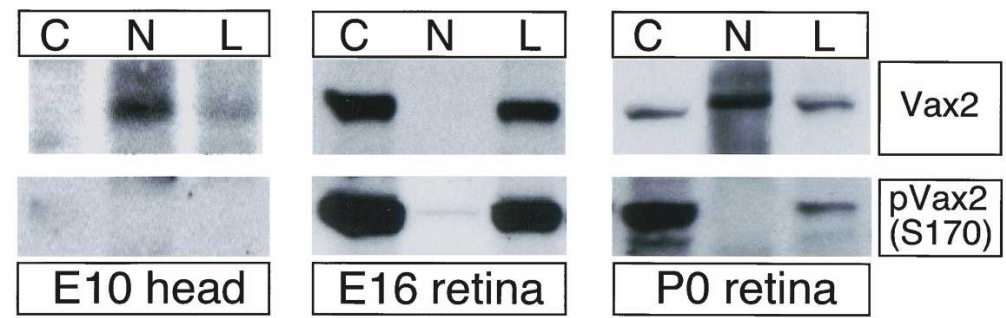

Figure 4. Phosphorylation of S170 is required for the cytoplasmic localization of Vax2. Schwann cells were transfected with a variety of Myc-Vax2 mutant cDNAs that encode Vax2 proteins with single, double, and triple mutations of Ser 170, Ser 172, and Ser 174 to either alanine or aspartic acid. Subcellular localization of the mutant proteins was monitored by immunostaining with anti-Myc antibody (green) and DAPI (blue). S170A, for example, is a Vax2 protein in which Ser 170 is mutated to alanine (B) and DSD is a Vax2 protein in which both Ser 170 and Ser 174 are mutated to aspartic acid (O). See text for details. (U) S170 phosphorylation of Vax2 marks cytoplasmic localization in vivo. Cell lysates (L) from embryonic heads (E10.5) or retina (E16 and P0) were separated into cytoplasmic (C) and nuclear (N) fractions by low-speed centrifugation, and then analyzed for the presence of Vax2 and S170-phosphoylated Vax2 [pVax2(S170)] by Western blotting with the indicated antibodies.

S172A mutations (Fig. 4D-F) did not significantly affect subcellular localization. Interestingly, the phosphomimicking S172D mutation modestly potentiated nu- clear Vax2 expression (Fig. 4G). Although this effect is consistent with a weak stimulation of nuclear localization by CKII phosphorylation at S172, a series of S170/ 
S172 double mutations clearly demonstrated that the phosphorylation status of S170 is the dominant determinant of localization, since Vax2 proteins incapable of being phosphorylated at S170 were always exclusively nuclear, independent of the phosphorylation status of S172 (Fig. 4H-K, Q-S). Similarly, double-mutant analyses indicated that Vax2 localization was independent of the phosphorylation status of S174. S170A mutants were exclusively nuclear independent of the status of S174 (Fig. 4H-K,Q-S), and conversely, S170D mutants were always predominantly cytoplasmic (Fig. 4L-P,T).

In light of these observations in cell culture, we sought to assess the importance of S170 phosphorylation to the subcellular localization of Vax2 in retinal cells in vivo. We generated an antibody specific for Vax2 that is singly phosphorylated at S170 (see Materials and Methods; Supplementary Fig. 1), and used this reagent to monitor the appearance and localization of phospho-Vax2 [pVax2(S170)] during retinal development in mouse embryos. We probed Western blots of tissue homogenates prepared from E10 head and from E16 and P0 retina, which were separated into crude nuclear and cytoplasmic fractions, as for Figure 1D above (Fig. 4U). At E10, Vax2 is an exclusively nuclear protein (Fig. 1), and consistent with this, the anti-pVax2(S170) antibody fails to detect a band in any fraction (Fig. 4U, left panels). By E16, essentially all Vax2 protein is cytoplasmic (Fig. 1; Supplementary Fig. 2), and correspondingly, antipVax2(S170) reactivity is restricted to the cytoplasmic fraction of the E16 retinal lysates (Fig. 4U, middle panels). At P0, Vax2 protein is present in both cytoplasmic and nuclear fractions (Fig. 1; Supplementary Fig. 2), but phospho-Vax2(S170) is only detected in the cytoplasmic fraction (Fig. 4U, right panels). These results demonstrate that phosphorylation of Vax2 at S170 is strictly correlated with cytoplasmic localization in vivo.

\section{Cytoplasmic localization is regulated through phosphorylation by PKA}

The effects of PKA activation on the expression of Vax2 in cultured Schwann cells and in the retina were also studied (Supplementary Fig. 4). We treated cultured Schwann cells with either (1) forskolin, which leads to the elevation of intracellular cAMP and thereby activates PKA, or (2) the PKA inhibitor KT5720. Nuclear versus cytoplasmic localization of endogenous Vax2 under both conditions, in comparison to no treatment, was then assessed. Vax1 was observed to be nuclear under all conditions (data not shown). In contrast, Vax2 was distributed between the nucleus and cytoplasm in the absence of treatment, but was shifted to the cytoplasm in the presence of forskolin (Supplementary Fig. 4). Conversely, treatment of Schwann cells with KT5720 resulted in Vax2 accumulation in the nucleus (Supplementary Fig. 4). Similar effects on Vax2 subcellular localization were observed in retinal explant cultures (Supplementary Fig. 4). Consistent with these observations in culture, we observed an inverse relationship between PKA activity and Vax2 nuclear localization in the devel- oping retina in vivo. We assessed PKA activity indirectly, using an antibody specific for the form of the cAMP response element-binding protein (CREB) that is phosphorylated on Ser 133 by PKA (pCREB) (Arias et al. 1994), and found that pCREB levels are low in the primitive ventral retina at E10, but high at E15 (data not shown). All of these data, together with the in vitro phosphorylation data of Supplementary Figure 3, are consistent with the conclusion that PKA activation promotes cytoplasmic localization of Vax2 through phosphorylation of S170. They do not, however, exclude the possibility that additional protein kinases may also phosphorylate Vax2 at this site.

\section{Shh drives Vax2 into the nucleus}

Given that nuclear expression is most prominent at E10.5, when the optic neuroepithlium is most closely apposed to the ventral midline, we examined extracellular cues that are known to be expressed at the ventral midline for their ability to regulate Vax2 localization. We focused on Shh, which is expressed at high levels at the ventral midline of the vertebrate forebrain and displays a high ventral-proximal to low dorsal-distal gradient in the optic vesicle (Echelard et al. 1993; Marti et al. 1995). Reciprocal cross-repression by Hedgehog and PKA is essential for development of the Drosophila retina ( $\mathrm{Li}$ et al. 1995; Pan and Rubin 1995; Strutt et al. 1995; Chen et al. 1998), and similar cross-repression has been hypothesized to play a role in vertebrate eye development (Hammerschmidt et al. 1996; Ungar and Moon 1996).

We first assessed the ability of Shh to effect the localization of Vax2 in cultured Schwann cells, which express endogenous Vax2 (Bertuzzi et al. 1999) as well as the components of the Shh transduction pathway (Parmantier et al. 1999). In the presence of both the 19-kD Nterminal active fragment of Shh and low concentrations of forskolin $(2 \mu \mathrm{M})$, Vax2 was evenly distributed between the Schwann cell nucleus and cytoplasm, and the levels of phospho-CREB were low (Fig. 5, top row). Under these same conditions, treatment with cyclopamine, a chemical inhibitor of Shh signaling, resulted in cytoplasmic localization of $\operatorname{Vax} 2$ and its exclusion from the nucleus (Fig. 5, second row). This treatment also led to a marked elevation of nuclear phospho-CREB (Fig. 5, second row), consistent with cross-repression between the Shh and PKA pathways. Cyclopamine-induced cytoplasmic localization was almost entirely dependent upon phosphorylation of Ser 170, since the S170A Vax2 mutant was largely confined to Schwann cell nuclei, even when these cells were treated with cyclopamine (Fig. 5, third row). Potentiation of Shh signaling through the expression of an activated form of the Shh transducer Smoothened (Smo-M2) resulted in exclusively nuclear localization of Vax2 (Fig. 5, fourth row). Nuclear localization driven by activated Smoothened was antagonized by cyclopamine (Fig. 5, fifth row). Remarkably, the ability of the activated Smo-M2 protein to promote nuclear localization was also dependent on Ser 170, since expression of the S170D Vax2 mutant, which mimics phosphoryla- 


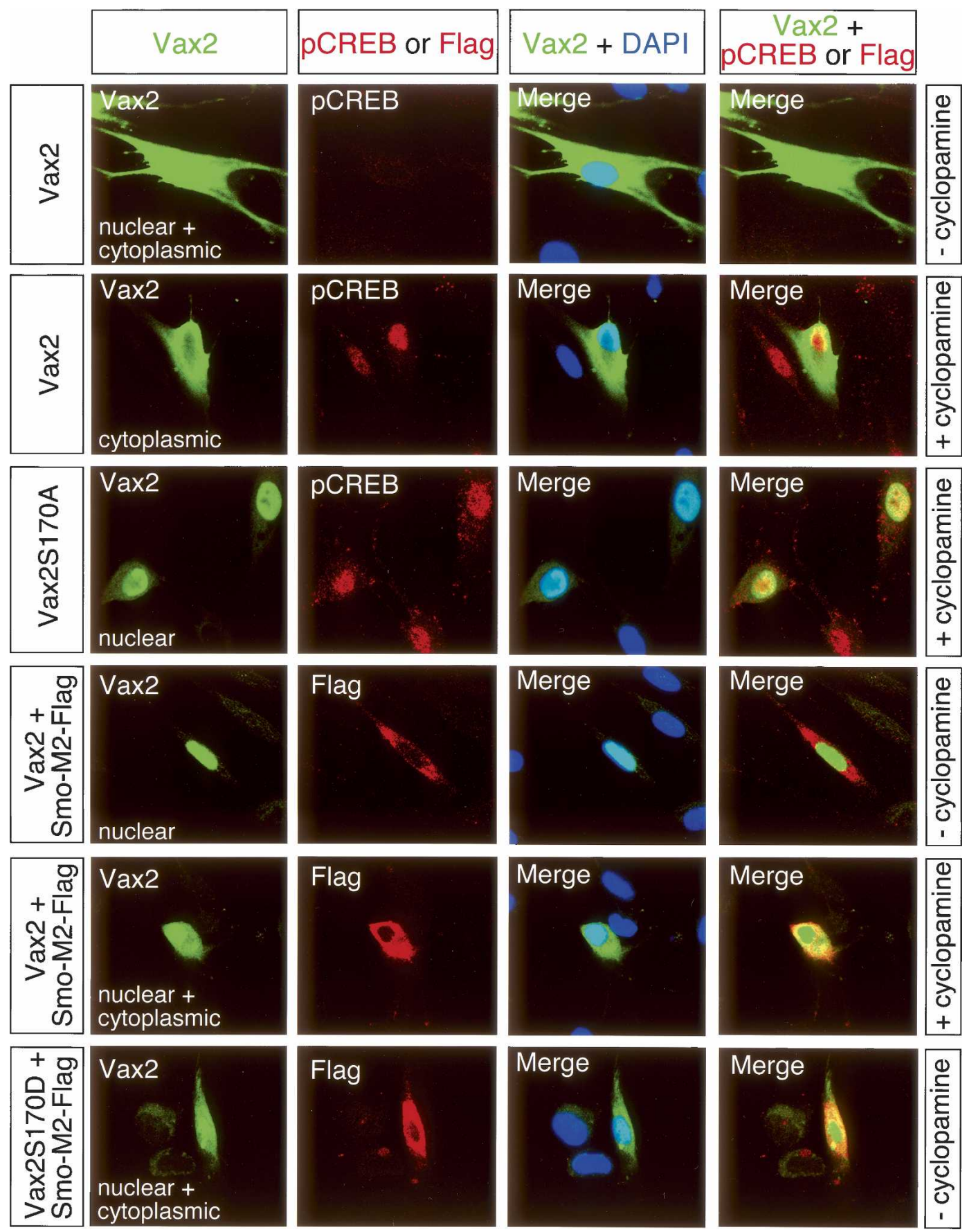

Figure 5. Activation of the Shh signaling pathway drives Vax2 nuclear accumulation and is dependent on Ser 170. Wild-type or S170A/D mutant forms of Myc-tagged Vax2 was expressed in Schwann cells-with or without constitutively active Flag-Smo-M2 (Incardona et al. 2002) and with and without the Shh inhibitor cyclopamine. Cells were treated with $200 \mathrm{nM}$ cyclopamine for $4 \mathrm{~h}$ prior to fixation. Cells were costained with rabbit anti-Vax2 antibody (green) and goat anti-pCREB antibody (red), or rabbit anti-Vax2 antibody (green) and mouse anti-Flag antibody (red). Nuclei were visualized with DAPI (blue).

tion at this site, led to significant accumulation of Vax2 in the cytoplasm, even in the presence of activated Smoothened (Fig. 5, bottom row). All of these data are consistent with the hypothesis that Shh promotes Vax2 nuclear accumulation, and that this is achieved through inhibition of PKA phosphorylation of S170.

Shh is the major hedgehog subtype governing the ven- tral patterning of the vertebrate eye (Ekker et al. 1995 Chiang et al. 1996), and the expression of Vax2, Vax1, and Pax2 in the ventral eye field is dependent on Shh (Macdonald et al. 1995; Take-uchi et al. 2003). We asked whether Shh induction of the Vax2 gene proceeds through a "classical" signaling pathway involving transcription factors of the Gli family. In this pathway, Shh 
binding to its receptor patched (Ptc) relieves Ptc inhibition of the multipass membrane protein Smoothened (Smo), which in turn stabilizes nonproteolyzed versions of transcription factors of the Gli family (vertebrate homologs of Cubitus interruptus in Drosophila). In the developing eye field in the mouse, the most prominent member of this family is Gli3, which exhibits repressor activity with respect to the development of ventral eye field structures (Litingtung and Chiang 2000; Aoto et al. 2002; Rallu et al. 2002; Furimsky and Wallace 2006).
We examined the expression and localization of Vax2 and Pax6 in the E10.5 optic neuroepoithelium of mice carrying mutations in both the Shh and Gli3 genes. Shh single mutants exhibit a dramatic phenotype in the eye field, characterized by cyclopia and a complete failure in ventral specification (Chiang et al. 1996). As illustrated in Figure 6, we found that these $S h h^{-/}$mutants express no Vax2 protein (Fig. 6C,H), consistent with an absolute requirement for $\mathrm{Shh}$ in the induction of the mouse $\operatorname{Vax} 2$ gene. Gli3 single mutants display a phenotype in which

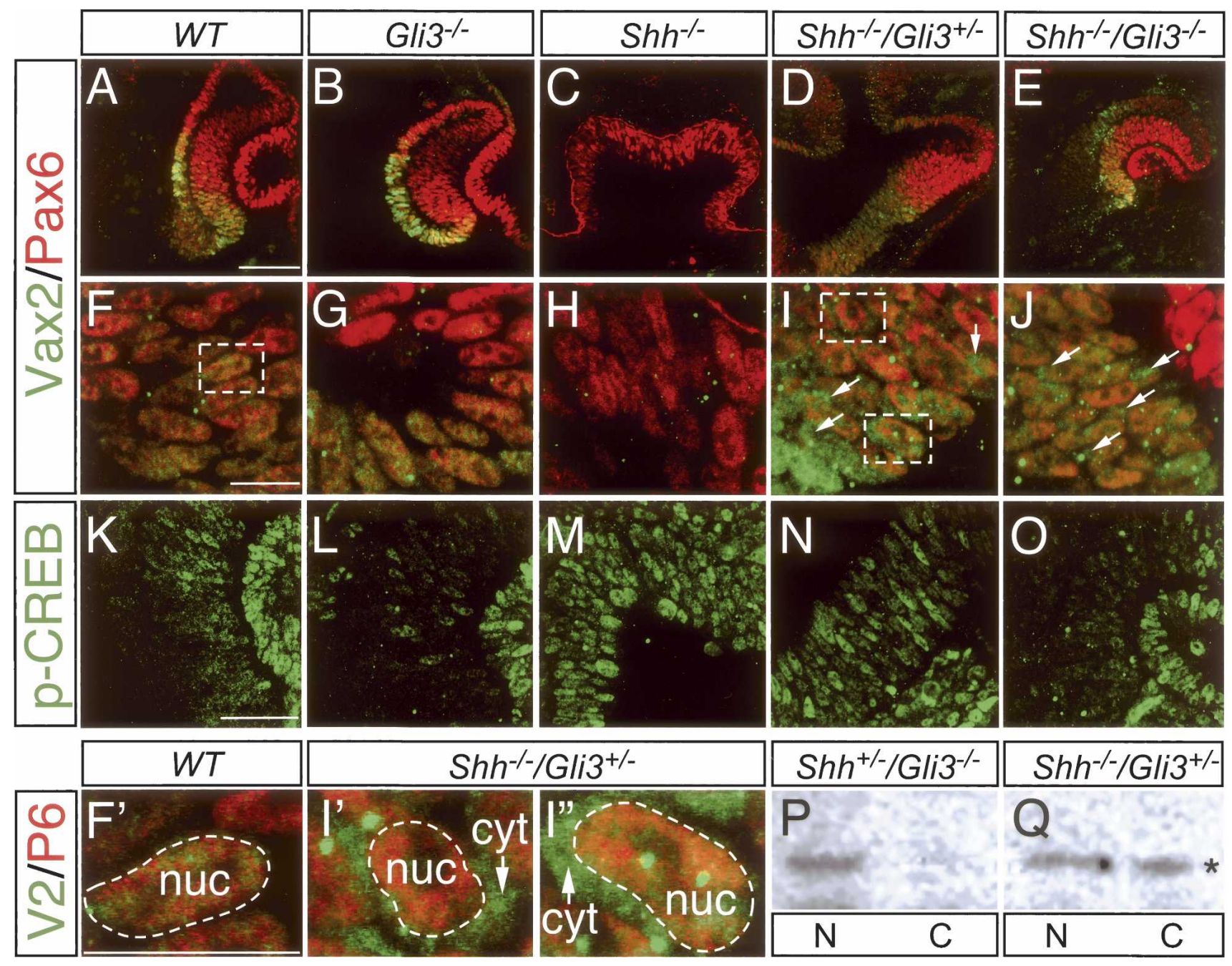

Figure 6. Cytoplasmic Vax2 in the E10.5 optic vesicle of Shh/Gli3 double mutants. $(A-J)$ Ten-micrometer sections of E10.5 wild-type

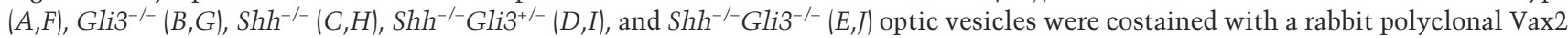
antibody (green) and mouse monoclonal Pax6 antibody (red). F-J are higher-power views of $A-E$, respectively. Pax6 was always detected in the nuclei of wild-type or mutant optic vesicles (see also Fig. 1), and was used to delineate nuclear boundaries. Vax2 was detected in the cytoplasm as well as the nuclei of $\mathrm{Shh}^{-/-} \mathrm{Gli3}^{+/-}$mice (arrows in I) and $\mathrm{Shh}^{-/-} \mathrm{Gli3}^{-/-}$mice (arrows in I), in contrast to its exclusively nuclear localization in wild-type $(F)$ and $G l i 3^{-/-}(G)$ mice. $(C, H)$ Consistent with the previous demonstration of Vax2 induction by Shh in zebrafish (Take-uchi et al. 2003), Vax2 could not be detected in the cyclopic Shh ${ }^{-/-}$optic vesicle. Boxed areas in $F$ and $I$ are enlarged in $F^{\prime}, I^{\prime}$, and $I^{\prime \prime}$ to highlight the absence of Vax2 in the cytoplasm of wild-type neuroepithelial cells $\left(F^{\prime}\right)$, and its presence in the cytoplasm of $S h h^{-/-} G l i 3^{+/-}$cells $\left(I^{\prime}\right.$, upper box in $I$; and $I^{\prime \prime}$, lower box in $\left.I\right)$. (K-O) Activity of PKA in the wild-type or mutant optic vesicle, as indirectly monitored by immunostaining for pCREB, in sections adjacent to those used for Vax2/Pax6 staining. $(L, O)$ Note that the $\mathrm{pCREB}$ staining is significantly reduced in both $G l i 3^{-/-}$genotypes. Bars: $A$ (for $\left.A-E\right), 100 \mu \mathrm{m} F($ for $F-J), F^{\prime}\left(\right.$ for $\left.F^{\prime}-I^{\prime \prime}\right)$, $20 \mu \mathrm{m} ; K$ (for $K-O), 50 \mu \mathrm{m}$. (P) Western blot of nuclear $(\mathrm{N})$ and cytoplasmic (C) fractions of an E10-E10.5 whole-embryo lysate prepared from a $\mathrm{Shh}^{+/-} \mathrm{Gli3}^{-/-}$mouse, probed with anti-Vax2. Consistent with the immunostaining of $G$, intact Shh signaling results in exclusively nuclear Vax2 localization. (Q) Similar Western blot from a Shh ${ }^{-/-} \mathrm{Gli3}^{+/-}$embryo. In the absence of Shh, $\sim 50 \%$ of Vax2 protein is now seen in the cytoplasmic fraction of the lysate (asterisk). 
the ventral domain of the eye field is modestly extended dorsally (distally from the ventral midline), and this is reflected in a distal expansion of the expression domain of Vax2 (Fig. 6B) and of Vax1 and Pax2 (data not shown). Perhaps most dramatic is the rescue of a nearly normal early eye field morphology, with no apparent cyclopia, in $\mathrm{Shh}^{-1-} \mathrm{Gli}^{+/-}$and $\mathrm{Shh}^{-/-} \mathrm{Gli3}^{-/-}$double mutants (Litingtung and Chiang 2000; Rallu et al. 2002). We find that expression of both Vax2 and Pax6, in their normal domains, is restored in these double mutants (Fig. 6D,E,I,J). Together, these results indicate that Shh induction of the mouse Vax2 gene is transduced through and suppressed by Gli3.

Most importantly, the $\mathrm{Shh}^{-/-} \mathrm{Gli3}^{+/-}$and $\mathrm{Shh}^{-/} \mathrm{Gli3}^{-/-}$ double mutants provide an in vivo setting in which Vax2 protein is expressed in the absence of Shh. This allows for dissociation of the effect of Shh on Vax2 induction from its effect on Vax2 subcellular localization. We find that the Vax2 protein that is expressed at the optic vesicle stage (E10-E10.5) of Shh ${ }^{-/-} \mathrm{Gli3}^{-/-}$and $\mathrm{Shh}^{-/-}$. $\mathrm{Gli3}^{+/-}$double mutants is present in both the nucleus and cytoplasm of cells of the ventral retinal neuroepithelium (Fig. $\left.6 \mathrm{I}, \mathrm{J}, \mathrm{I}^{\prime}, \mathrm{I}^{\prime \prime}\right)$, in marked contrast to the exclusively nuclear localization of $\operatorname{Vax} 2$ seen in wild-type mice at this time (Fig. 6F, $\mathrm{F}^{\prime}$ ). Indeed, the cytoplasmic expression of Vax2 that we observe immunocytochemically in $\mathrm{Shh}^{-/-} \mathrm{Gli3}^{-/-}$double mutants would in principle be even more pronounced were it not for the fact that PKA signaling - as evidenced by p-CREB immunostaining-is significantly reduced in both $\mathrm{Gli3}^{-/-}$genotypes (Fig. 6L,O). Note that the level of both cytoplasmic expression of Vax2 and phospho-CREB is higher in $\mathrm{Shh}^{-1-} \mathrm{Gli}^{+/-}$mice (Fig. 6I,N) than in $\mathrm{Shh}^{-/-} \mathrm{Gli3}^{-/-}$mice (Fig. 6J,O). We confirmed these immunocytochemical results by analyzing nuclear versus cytoplasmic localization of Vax2 in E10E10.5 whole embryo lysates that were separated into nuclear and cytoplasmic fractions by low-speed centrifugation and then analyzed by Western blot, as in Figure 1D (Fig. 6P,Q). In Shh ${ }^{+/} \mathrm{Gli3}^{-/-}$embryos, in which Shh signaling is maintained, Vax2 protein was detected only in the nuclear fraction of the lysates (Fig. 6P), consistent with the exclusively nuclear localization detected immunocytochemically (Fig. $6 \mathrm{~F}^{\prime}$ ). In contrast, in $\mathrm{Shh}^{-/-} / \mathrm{Gli3}^{+/-}$ embryos, in which Shh signaling is lost, Vax2 was equally distributed between nuclear and cytoplasmic fractions of embryo lysates (Fig. 6Q), consistent with the immunocytochemical detection of Vax2 in both the nucleus and cytoplasm of E10 neuroepithelial cells (Fig. $\left.6 \mathrm{I}^{\prime}, \mathrm{I}^{\prime \prime}\right)$. Taken together, all of these in vivo findings demonstrate that Shh both induces the Vax2 gene and at the same time promotes nuclear localization of the Vax 2 protein.

\section{Retinal development is blocked by constitutive nuclear expression of Vax2}

The two-phase model for Vax2 regulation of eye patterning requires the disabling of Vax2 repression of the Pax6 gene after approximately E12.5. This could in theory be achieved by inactivating the Vax 2 protein, by converting it from a repressor to an activator, or by expelling it from the nucleus. We therefore asked whether the regulated Vax2 subcellular localization that we observe during retinal differentiation is truly essential to normal eye development. The alternative is that trafficking is an incidental epiphenomenon of no developmental consequence.

We used in ovo electroporation to introduce a series of retroviral (RCAS) Vax2 expression constructs into the chick optic vesicle. We performed these electroporations at E1.5 (Hamburger and Hamilton [HH] stage 10-12), and then analyzed the electroporated embryos at E7.5. We injected 20 ng of DNA per embryo, except for the phospho-mimicking S170D construct, where we frequently introduced 10-fold higher levels of DNA per embryo (see Materials and Methods). Retroviruses produced by the RCAS vectors we used carry an IRES-GFP marker and are replication competent; they lead to expression in nearly all cells of the developing eye (McLaughlin et al. 2003).

The results of these experiments are illustrated in Figure 7A-J. Frontal views of the head of each E7.5 embryo are shown in the center panels of each row (Fig. $7 \mathrm{~A}, \mathrm{C}, \mathrm{F}, \mathrm{I}$ ), with lateral views of the experimental (electroporated) and control sides of the embryo on the right and left, respectively. Electroporation of $20 \mathrm{ng}$ of an empty RCAS vector did not perturb chick eye development (Fig. 7A), whereas the same amount of RCAS DNA encoding wild-type Vax2, which partitions into both the nucleus and cytoplasm in cells in culture (Figs. 2B, 3C, $4 \mathrm{~A}$ ) and in cells of the chick retina (Supplementary Fig. 5), modestly but appreciably antagonized eye development (Fig. 7B-D). In marked contrast, the Vax2S170A protein, which is exclusively nuclear (Fig. 4B; Supplementary Fig. 5), exhibited a dramatic effect, obliterating eye development entirely (Fig. 7E-G). As a control for the specificity of this effect, we injected $200 \mathrm{ng}(10 \times)$ of RCAS encoding the Vax2S170D protein, which is predominately cytoplasmic (Fig. 4C; Supplementary Fig. 5). These injections consistently yielded embryos with only modestly smaller and relatively normal-looking eyes (Fig. 7H-J). All of the effects on eye development illustrated in Figure 7A-J were reproducibly seen over multiple sets of injections (Supplementary Table 1). We performed a similar set of electroporations (data not shown) in which we also included a Pax6 $\alpha$-enhancer-driven lacZ reporter construct ( $\alpha$-lacZ) (Kammandel et al. 1999). Vax2 binding and repression of Pax6 transcription through the retinal $\alpha$-enhancer is essential to optic nerve development and is incompatible with retinal differentiation (Mui et al. 2005). Extracts prepared at E4 (2.5 d after electroporation) from the heads of embryos expressing the consitutively nuclear Vax2S170A protein exhibited a 250 -fold reduction in $\beta$-gal-specific activity driven by the Pax $6 \alpha$-enhancer, relative to $\alpha$-lacZ coelectroporated with empty RCAS alone (data not shown).

Finally, we examined Pax2 and Pax6 protein expression in sections of the optic neuroepithelium. We sectioned through both the experimental and control sides of E7.5 Vax2S170A embryos and then immunostained for Pax2 and Pax6 proteins in the eye field (Fig. 7K-R). 

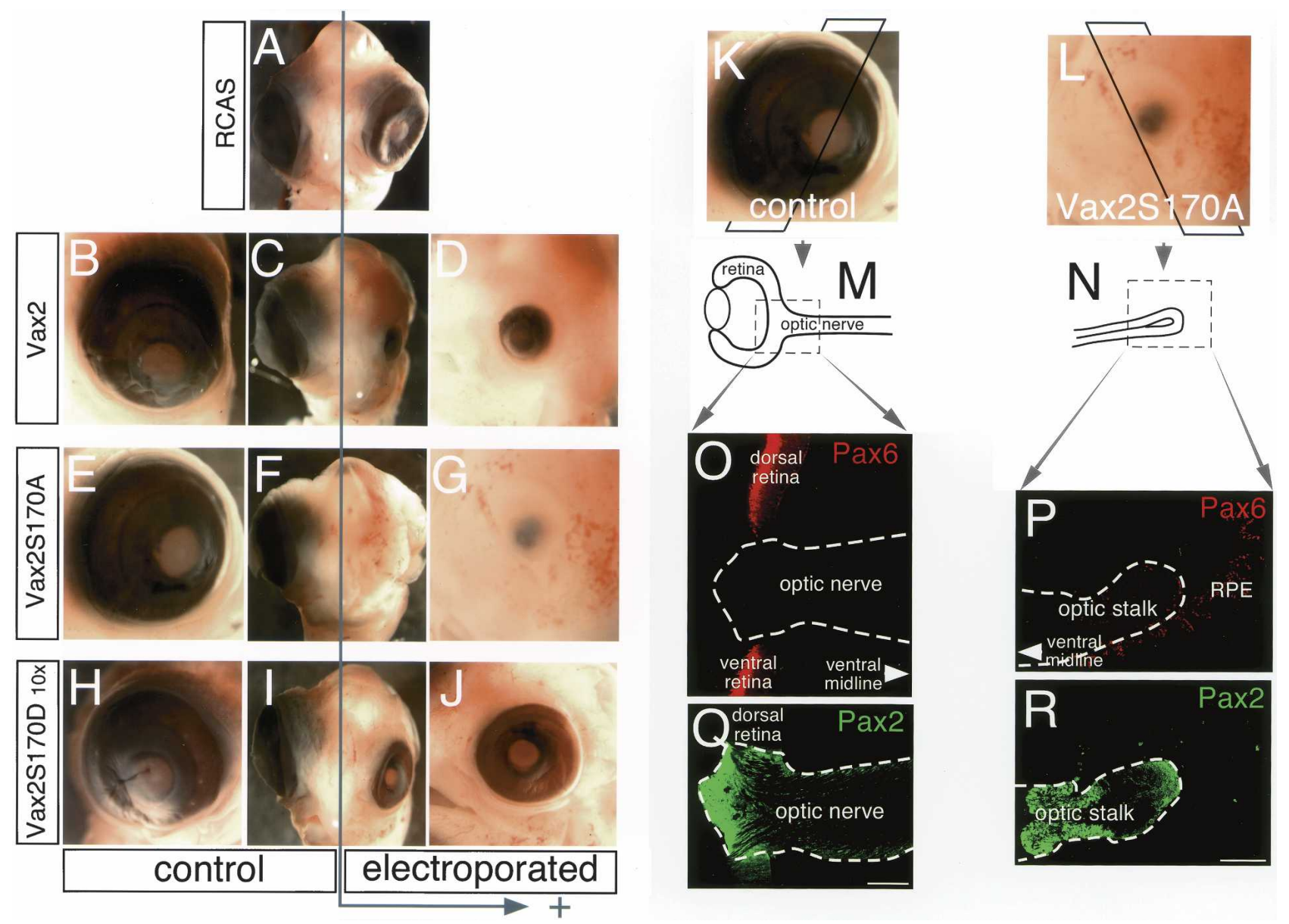

Figure 7. Maintained nuclear expression of Vax2 blocks retinal development. Chick optic vesicles (E1.5; HH stage 11-12) were unilaterally electroporated (arrow; right side of the figure) with RCAS-IRES-EGFP $(A)$, RCAS-Vax2-IRES-EGFP $(D)$, RCAS$\operatorname{Vax} 2($ S170A)-IRES-EGFP $(G)$, or RCAS-Vax2(S170D)-IRES-EGFP $(J)$. We injected a total of $20 \mathrm{ng}$ of DNA per embryo $(A-G)-$ except for the phospho-mimicking S170D construct $(H-J)$, where we introduced 10-fold higher levels of DNA per embryo. Images are frontal $(A, C, F, I)$ and lateral $(B, D, E, G, H, J)$ views of electroporated embryos at E7.5. $D, G$, and $J$ are the electroporated sides of each embryo, and $B, E$, and $H$ are the control sides. (The expression of the electroporated Vax2 genes is confirmed in Supplementary Fig. S5). (K,L) E7.5 control $(K)$ and Vax2 S170A electroporated $(L)$ eyes, corresponding to those in $E$ and $G$, respectively, were cryosectioned at $16 \mu m$ as indicated by the superimposed frames, to generate the sections schematized in $M$ and $N .(O, P)$ These sections were stained with an

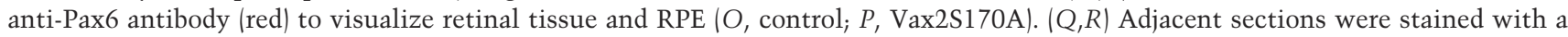
Pax2 antibody (green) to visualize optic stalk/nerve tissue. A sharp border between Pax2-positive optic nerve astrocytes and Pax6positive retinal cells is observed in the control $(O, Q)$, whereas there is only a Pax2-positive optic stalk, and no Pax6-positive retina, which develops from the Vax2S170A-electroporated neuroepithelium $(P, R)$. Bars, $100 \mu \mathrm{m}$.

Sections through the large control eye (Fig. 7K) were examined in the region where the optic nerve head inserts into the retina (boxed area in the schematic of Fig. 7M). As expected, the Pax6 and Pax2 proteins in this unelectroporated eye were detected in their previously described nonoverlapping domains, with Pax6 in the retina (Fig. 7O) and Pax2 in the optic nerve (Fig. 7Q). There was no eye evident on the electroporated side of E7.5 Vax2S170A embryos (Fig. 7L), and sections through the optic neuroepithelium of these embryos yielded only a small, optic-stalk-like stump extending out from the ventral midline (schematized in Fig. $7 \mathrm{~N}$ ), with an associated ribbon of RPE. Staining of this tissue revealed minimal Pax6 expression (except for the RPE ribbon) (Fig. 7P), but abundant expression of Pax2 (Fig. 7R), as if the eye field had failed to generate any retinal tissue and instead produced only an optic nerve rudiment. Together, the data in Figure 7 indicate that maintained nuclear expression of Vax2 is incompatible with the development of an eye.

\section{Discussion}

Many transcription factors move between the nucleus and cytoplasm of cells in response to changes in cellular environment, and for several transcription factor families-e.g., the STAT proteins, NFkB, and the SREBPsthe molecular mechanics of trafficking are now known in great detail (Hou et al. 2002; Rawson 2003; Xiao and Ghosh 2005). However, the significance of these phe- 
nomena to vertebrate development in general, and to the developing CNS in particular, is largely unknown.

Our results indicate that regulated and reversible nuclear-to-cytoplasmic shuttling provides a mechanism for staging development, by changing the developmental competence of a tissue over time. We demonstrate that forward development of the retina is driven by expelling Vax2 from the nucleus of differentiating neuroepithelial cells beginning around E12, and that development can proceed only by this mechanism. Vax2 is a transcriptional repressor that is required during noncontiguous developmental windows in the mouse-first at E9.5E11.5 to make an optic nerve (Mui et al. 2005) and then again $10 \mathrm{~d}$ later to establish dorsal-ventral polarity in the retina (Mui et al. 2002). In between these two windows, the retina itself is generated, and nuclear Vax2 would block this process. Utilization of Vax 2 throughout optic development could in theory be achieved by turning the Vax2 gene on, then off, and then on again. However, our data indicate that an equivalent punctuation in Vax2 activity is more efficiently achieved by using Shh and PKA to regulate Vax2 protein localization as a function of time.

The possibility that morphogen-induced differential localization of a transcription factor at different developmental time points might allow for the temporal regulation of gene expression has not been raised previously, and in those instances in which the shuttling of a transcription factor in the developing CNS has been previously documented, the biochemical mechanisms that control shuttling remain to be elucidated. The mammalian homeodomain protein Otx1, for example, is localized to the cytoplasm of cortical neuronal progenitors, and is mobilized to the nucleus only after these cells differentiate, migrate to their final laminar location, and elaborate extensive subcortical projections and connections. This relocalization is well correlated with the time at which Otx1 function is required for the refinement of these connections (Weimann et al. 1999; Zhang et al. 2002). Similarly, the basic helix-loop-helix (bHLH) protein Olig1 is a nuclear protein in developing oligodendrocytes throughout embryogenesis, but becomes localized to the cytoplasm postnatally. It is remobilized to the nucleus when adult oligodendrocyte progenitors are reactivated in response to demyelinating lesions (Arnett et al. 2004). Although the movement of these transcription factors into the nucleus is well correlated with the time in neural development at which they are known or thought to function, it is not clear whether transcription factor translocation out of the nucleus and into the cytoplasm is at all essential. A requirement for Otx1 or Olig1 movement, for example, has not been tested.

The data presented above demonstrate that (1) Vax2 shuttles between the nucleus and cytoplasm with a periodicity that is correlated with two distinct phases of mouse eye development; (2) this movement is controlled by the phosphorylation of Ser 170 of the Vax2 protein, most probably mediated by PKA; (3) the ventralizing morphogen Shh promotes nuclear localization of Vax2 by antagonizing S170 phosphorylation; and most importantly, (4) regulated trafficking is neither gratuitous nor incidental to eye development, but rather is an essential feature of retinal differentiation. Vax2 must be in the nucleus from E9.5-E11.5 (Mui et al. 2005), must be out of the nucleus by E16.5 (this study), and must return to the nucleus around P0 (Mui et al. 2002).

\section{Regulation of localization}

At the optic vesicle stage of eye development (approximately E9|, Vax2-expressing cells in the ventral optic neuroepithelium are closely apposed to the midline source of Shh. They are therefore exposed to relatively high levels of the morphogen, they express low levels of PKA activity as marked by pCREB, and their Vax2 protein is localized entirely to the nucleus. As development proceeds and the optic cup forms, Vax2-expressing cells are displaced to positions more and more removed from the midline and are thus exposed to lower levels of Shh. As a consequence, their Vax2 protein is increasingly localized to the cytoplasm, such that by E16.5, almost all of the protein is cytoplasmic. At this time, the Vax2positive cells are in the ventral retina proper, where Pax6 activity is required for continued retinal differentiation. Late in embryogenesis and during the first few days after birth, when Vax2 acts to establish DV retinal polarity, the protein is significantly remobilized to the nucleus.

This reciprocal push-pull regulation of Vax2 localization by PKA and Shh during development provides for fine spatial and rapid temporal control of transcription factor activity, neither of which could be achieved by simply turning the Vax2 gene on and off. While our data are consistent with the conclusion that PKA phosphorylates Vax2 directly, we do not exclude the possibility that PKA acts upstream of or in conjunction with an additional kinase that might also phosphorylate Vax2 on S170. There are several potential mechanisms through which Shh could antagonize this phosphorylation. For example, Shh signaling might inhibit PKA directly. Smoothened has been found to couple to and activate a $\mathrm{G}_{\alpha \mathrm{i}}$ protein that inhibits adenylate cyclase, leading to cAMP reduction and a consequent reduction in PKA activity (DeCamp et al. 2000), and Shh treatment of RGC neurons has also been found to result in a reduction in cAMP levels (Trousse et al. 2001). Alternatively, Shh signaling might result in the induction of a set of genes (e.g., one or more phosphatase genes) that could antagonize Vax2 phosphorylation. Deciphering the biochemistry of Shh inhibition of Vax2 phosphorylation represents an important avenue for future study. Although we favor the hypothesis that cytoplasmic Vax2 represents an inactive depot of protein that can be rapidly mobilized into the nucleus by Shh or other extracellular signals, we do not exclude the possibility that Vax2 may have some active function in the cytoplasm (e.g., Brunet et al. 2005). In addition, while our data clearly demonstrate that Shh is one cue that drives Vax2 into the nucleus, this mor- 
phogen may not be the only extracellular signal that does so during retinal development.

\section{Vax2 localization and Pax6 regulation}

Vax2 is a powerful repressor of Pax6 transcription, and since Pax6 is essential for retinal development, this repressor activity must be tightly controlled. In the E9-E10 ventral optic vesicle, Vax2 and Vax1 function cooperatively to repress Pax6 transcription, by binding to and inhibiting the activity of the Pax6 retinal $\alpha$-enhancer (Mui et al. 2005). In so doing, they drive differentiation of the optic nerve by inhibiting development of the retina. After approximately E12.5, expression of Vax1, which lacks the serine array required for the regulation of Vax2 localization (Fig. 3), is lost from the developing ventral retina and becomes confined to the astrocyte progenitors of the optic nerve. In these cells, Vax1 is a constitutively nuclear protein that continues to repress transcription of the Pax6 gene and continues to drive optic nerve development (Bertuzzi et al. 1999). In marked contrast, Vax2 mRNA is abundantly expressed in the ventral retina, to the end of mouse embryogenesis and beyond (Mui et al. 2002). Nuclear expression of the protein encoded by this mRNA would be incompatible with the ongoing differentiation of RGCs, amacrine cells, and other retinal cell types that require Pax6 during the last $10 \mathrm{~d}$ of embryogenesis. Correspondingly, the $\operatorname{Vax} 2$ protein is confined to the cytoplasm of differentiating retinal cells, where it cannot repress Pax6 transcription.

In this context, it is informative to compare the phenotypes of mouse Vax2 loss-of-function mutants (Barbieri et al. 2002; Mui et al. 2002) to those of the chick Vax2S170A chick gain-of-function mutants illustrated in Figure 7. Since Vax1 and Vax2 act cooperatively to segregate the developing optic nerve from retina, removal of Vax2 alone has only a minimal effect on early eye field morphology, instead leading to a loss of postnatal dorsal-ventral polarity in what is otherwise a relatively normal-looking eye and retina (Mui et al. 2002). This DV patterning defect specifically reflects the loss of the second phase of retinal Vax2 action early in postnatal development. In dramatic contrast, early embryonic expression of the Vax2S170A protein-which is a stable, perfectly functional transcription factor that is constitutively localized to the nucleus-ablates the eye entirely. This leads to the remarkable conclusion that it is far worse for eye development to have a Vax2 protein that cannot be shunted to the cytoplasm during late embryogenesis than it is to have no Vax2 protein at all.

The phenomena that we document for Vax2 are very likely to be relevant to the regulation of transcription factor activity during neural development generally. As noted above, several other transcription factors have been observed to be differentially localized to the nucleus or cytoplasm at different times in the developing vertebrate CNS. Indeed, subcellular shuttling as a function of developmental time may prove to be the rule rather than the exception. And in simpler systems, such as the Drosophila embryo, there are compelling ex- amples (e.g., Stathopoulos and Levine 2002) where regulation of transcription factor localization by extracelllular cues plays a critical role in the regulation of transcription factor activity. It is therefore not unreasonable to suggest that morphogens such as Hedgehogs, bone morphogenetic proteins, and Wnts may function in development as much through their ability to regulate the subcellular localization of transcription factors as through their ability to regulate the expression of genes.

\section{Materials and methods}

\section{Mouse lines}

Shh+/-Gli3 ${ }^{+/-}$mice (Litingtung and Chiang 2000) were obtained from Dr. Ching Chiang (Vanderbilt University, Nashville, $\mathrm{TN})$, and were used for the generation of $\mathrm{Shh}^{-/}, \mathrm{Shh}^{-/-} \mathrm{Gli3}^{+/-}$, and $\mathrm{Shh}^{-/-} \mathrm{Gli3}^{-/-}$mice. Vax1 $1^{-/-}$and $\mathrm{Vax}^{-/-}$mice were as described previously (Bertuzzi et al. 1999; Mui et al. 2002).

\section{DNA constructs}

Full-length cDNAs of Vax1 and Vax2 were subcloned into pCS2(+)-myc. DNA fragments encoding Vax2 deletion mutants were produced by PCR and subcloned into phrGFP-N1 (Stratagene). pCS2(+)-myc constructs encoding point mutants of Vax2 were generated by site-directed mutagenesis using pfu turbo DNA polymerase (Stratagene). For expression in chick embryos, PCR fragments encoding full-length wild-type and mutant Vax2 were subcloned into the RCAS-IRES-EGFP vector (McLaughlin et al. 2003). For the expression of GST-fused Vax2 and Vax2VD2 proteins, PCR fragments encoding full-length Vax2 or Vax2-VD2 were cloned into pGEX-4T1.

\section{Primary cell and explant cultures}

Primary Schwann cells were isolated from P3 rat sciatic nerves as described previously (Syroid et al. 1999). Cells were plated on poly-L-lysine-coated cover slips and maintained in Dulbecco's modified Eagle's medium (DMEM) supplemented with $10 \%$ fetal bovine serum (FBS), recombinant NRG- $1 \beta(10 \mathrm{ng} / \mathrm{mL})$, and 2 $\mu \mathrm{M}$ forskolin. Cells were transfected with DNA constructs using calcium phosphate precipitation. Retinal explant cultures were prepared using modified versions of previously published protocols (Wang et al. 2002). Briefly, retinae were isolated from E14 C57BL/6 mouse eyes and cultured on 13-mm polycarbonate filters in growth medium (1:1 DMEM-F12, 5\% FBS, $10 \mu \mathrm{g} / \mathrm{mL}$ insulin, $100 \mathrm{mg} / \mathrm{mL}$ transferin, $100 \mathrm{mg} / \mathrm{mL}$ BSA, $60 \mathrm{ng} / \mathrm{mL}$ progesterone, $16 \mu \mathrm{g} / \mathrm{mL}$ putrescine, $40 \mathrm{ng} / \mathrm{mL}$ sodium selenite, 20 $\mathrm{ng} / \mathrm{mL} \mathrm{BDNF}$ ) for $4 \mathrm{~h}$ in the presence of $20 \mu \mathrm{M}$ forskolin or $5 \mu \mathrm{M}$ KT5720, and then fixed for $30 \mathrm{~min}$ in $4 \%$ paraformaldehyde/ PBS. Explants were frozen in OCT after the cryoprotection in $20 \%$ sucrose/PBS and then cryosectioned.

\section{Antibodies and immunohistochemistry}

N-terminal fragments of Vax1 (amino acids 1-71) or Vax2 (amino acids 1-73) were fused to GST by cloning into pGEX$4 \mathrm{~T} 1$, and recombinant proteins were produced in E. coli BL21-DE3 (Stratagene). Rabbit polyclonal antibodies against GST-Vax1(1-71) or GST-Vax2(1-73) were produced by Stratagic Biosolutions, Inc. Antibodies recognizing GST-Vax1(1-71) or GST-Vax2(1-73) were isolated using a QuickPrep affinity purification kit (Sterogene Bioseparations). The phosphorylated peptide corresponding to the VD2 region of $\mathrm{Vax} 2 l_{\mathrm{NH} 2}$ 
QRSDLEKRAS $_{\mathrm{PO}_{3}}$ SSASEAFAT $_{-\mathrm{COOH}}$; produced by Global Peptide, Inc.) was used as immunogen to generate rabbit antipVax2(S170), which was also affinity-purified using the QuickPrep affinity purification kit.

For immunohistochemistry, embryos were fixed in $4 \%$ paraformaldehyde in PBS for 30 min and incubated in $20 \%$ sucrose/ PBS for $16 \mathrm{~h}$ followed by freezing in OCT. Sections were incubated for $1 \mathrm{~h}$ in a blocking solution that contained $5 \%$ normal donkey serum and 5\% normal goat serum in PBS, with $0.1 \%$ Triton X-100. Rabbit polyclonal antibodies against Vax1 (1:100), Vax2 (1:100), or phospho-CREB (1:100; Upstate Biotechnology) were coincubated with mouse monoclonal antibody against Pax6 (1:10; Developmental Studies Hybridoma Bank) for $16 \mathrm{~h}$ at $4^{\circ} \mathrm{C}$. Fluorescent images were obtained with a confocal microscope (LSM510; Zeiss) after staining with Cy3-conjugated donkey anti-mouse antibody and Alexa 488-conjugated anti-rabbit antibody for $1 \mathrm{~h}$.

For staining of cultured cells, transfected cells were fixed with $4 \%$ paraformaldehyde in PBS for 10 min, washed with PBS three times, and treated with $1 \%$ Triton X-100 for $15 \mathrm{~min}$. Cells were stained with mouse monoclonal antibody against Myc (1:1000; Cell Signaling Technology), rabbit polyclonal antibody against pCREB, goat polyclonal antibody against pCREB(Ser133) (1:100; Santa Cruz Biotechnology), or mouse monoclonal antibody against Flag (1:1000; Sigma).

\section{Nuclear fractionation and Western blotting}

Embryonic tissues were chopped into small pieces and dissociated by incubation in $0.25 \%$ trypsin-EDTA for $10 \mathrm{~min}$ at $37^{\circ} \mathrm{C}$, followed by three PBS washes. Cell pellets were resuspended in swelling buffer containing $10 \mathrm{mM}$ potassium acetate, $15 \mathrm{mM}$ magnesium acetate, $0.1 \mathrm{M}$ Tris (pH 7.6), $0.5 \mathrm{mM}$ phenylmethylsulfonyl fluoride, and protease inhibitor cocktail (Roche), and then incubated on ice for $20 \mathrm{~min}$, before Dounce homogenization. Nuclei were collected by centrifugation at $3300 \times \mathrm{g}$ for 15 min, and the resulting cytoplasmic supernatant was removed and retained. Nuclei were resuspended in lysis buffer $(1 \%$ sodium dodecyl sulfate [SDS], $10 \mathrm{mM}$ EDTA, $50 \mathrm{mM}$ Tris- $\mathrm{HCl}$ at $\mathrm{pH}$ 8.1, protease inhibitor cocktail [Roche]) and incubated on ice for $10 \mathrm{~min}$ followed by centrifugation at $10,000 \times \mathrm{g}$ for $15 \mathrm{~min}$. Protein in each fraction $(100 \mu \mathrm{g})$ was separated by $10 \%$ SDSPAGE and analyzed by Western blotting with anti-Vax1 or antiVax2 antibody followed by peroxidase-conjugated anti-rabbit IgG (Amersham-Phamacia). Bands were visualized by exposure to X-ray film after incubating in Super Signal solution (Pierce).

\section{Protein phosphorylation}

For phosphorylation analysis, GST fusion proteins were diluted in a suitable reaction buffer for each kinase (provided by the vendor) and then incubated for $30 \mathrm{~min}$ at $30^{\circ} \mathrm{C}$ with $1 \mathrm{U}$ of protein kinase and $\left[{ }^{32} \mathrm{P}\right]-\gamma$-ATP $(100 \mu \mathrm{Ci} / \mathrm{mL}$; Amersham-Pharmacia Biotech.). Reactions were stopped by boiling for $5 \mathrm{~min}$ in SDS-sample buffer, and were analyzed by SDS-PAGE followed by exposure in a PhosphorImager (Molecular Dynamics).

\section{Retroviral vector electroporation into chick embryos}

Injection and electroporation of retroviral constructs were carried out according to previously published procedures (McLaughlin et al. 2003). In brief, fertilized eggs of white Leghorn chickens were incubated at $38^{\circ} \mathrm{C}$ for $36 \mathrm{~h}$ prior to the electroporation. At stages 10-12 (Hamburger and Hamilton 1992), 30 $\mathrm{nL}$ of DNA solution carrying RCAS-IRES-EGFP constructs containing wild-type Vax2 (RCAS-Vax2-IRES-EGFP), Vax2(S170A)
[RCAS-Vax2(S170A)-IRES-EGFP], or Vax2(S170D) [RCASVax2(S170D)-IRES-EGFP] were injected into the diencephalic ventricular space after mixing with Fast Green dye. Five square pulses of $50 \mathrm{msec}$ at $25 \mathrm{~V}$ were applied by a T820 Electrosquare porator (BTX) through parallel platinum-coated electrodes (4$\mathrm{mm}$ space), which were placed alongside the embryo covered with L15 medium. Six days later (E7.5), embryos were dissected, fixed in $4 \%$ paraformaldehyde in PBS, sectioned, and examined for the expression of Vax2 and GFP using confocal microscopy.

\section{Acknowledgments}

We thank Drs. Stina Mui and Stefano Bertuzzi for continuing discussion and Joe Hash for outstanding technical support. We thank Dr. Ching Chiang for the generous gift of Shh/Gli3 mutant mice and Dr. Henk Roelink for the Flag-Smo-M2 construct. This work was supported by a grant from the NIH (to G.L.) and by a Long-term Fellowship from the Human Frontier Science Program (to J.W.K.).

\section{References}

Aoto, K., Nishimura, T., Eto, K., and Motoyama, J. 2002. Mouse GLI3 regulates Fgf8 expression and apoptosis in the developing neural tube, face, and limb bud. Dev. Biol. 251: 320332.

Arias, J., Alberts, A.S., Brindle, P., Claret, F.X., Smeal, T., Karin, M., Feramisco, J., and Montminy, M. 1994. Activation of cAMP and mitogen responsive genes relies on a common nuclear factor. Nature 370: 226-229.

Arnett, H.A., Fancy, S.P., Alberta, J.A., Zhao, C., Plant, S.R., Kaing, S., Raine, C.S., Rowitch, D.H., Franklin, R.J., and Stiles, C.D. 2004. bHLH transcription factor Olig1 is required to repair demyelinated lesions in the CNS. Science 306: 2111-2115.

Barbieri, A.M., Broccoli, V., Bovolenta, P., Alfano, G., Marchitiello, A., Mocchetti, C., Crippa, L., Bulfone, A., Marigo, V., Ballabio, A., et al. 2002. Vax2 inactivation in mouse determines alteration of the eye dorsal-ventral axis, misrouting of the optic fibres and eye coloboma. Development 129: 805813.

Bertuzzi, S., Hindges, R., Mui, S.H., O'Leary, D.D., and Lemke, G. 1999. The homeodomain protein vaxl is required for axon guidance and major tract formation in the developing forebrain. Genes \& Dev. 13: 3092-3105.

Brunet, I., Weinl, C., Piper, M., Trembleau, A., Volovitch, M., Harris, W., Prochiantz, A., and Holt, C. 2005. The transcription factor Engrailed-2 guides retinal axons. Nature 438: 9498.

Chen, Y., Gallaher, N., Goodman, R.H., and Smolik, S.M. 1998. Protein kinase A directly regulates the activity and proteolysis of cubitus interruptus. Proc. Natl. Acad. Sci. 95: 23492354.

Chiang, C., Litingtung, Y., Lee, E., Young, K.E., Corden, J.L., Westphal, H., and Beachy, P.A. 1996. Cyclopia and defective axial patterning in mice lacking Sonic hedgehog gene function. Nature 383: 407-413.

Chow, R.L. and Lang, R.A. 2001. Early eye development in vertebrates. Annu. Rev. Cell Dev. Biol. 17: 255-296.

Chow, R.L., Altmann, C.R., Lang, R.A., and Hemmati-Brivanlou, A. 1999. Pax6 induces ectopic eyes in a vertebrate. Development 126: 4213-4222.

DeCamp, D.L., Thompson, T.M., de Sauvage, F.J., and Lerner M.R. 2000. Smoothened activates G $\alpha$ i-mediated signaling in 
frog melanophores. J. Biol. Chem. 275: 26322-26327.

Echelard, Y., Epstein, D.J., St-Jacques, B., Shen, L., Mohler, J., McMahon, J.A., and McMahon, A.P. 1993. Sonic hedgehog, a member of a family of putative signaling molecules, is implicated in the regulation of CNS polarity. Cell 75: 14171430.

Ekker, S.C., Ungar, A.R., Greenstein, P., von Kessler, D.P., Porter, J.A., Moon, R.T., and Beachy, P.A. 1995. Patterning activities of vertebrate hedgehog proteins in the developing eye and brain. Curr. Biol. 5: 944-955.

Furimsky, M. and Wallace, V.A. 2006. Complementary Gli activity mediates early patterning of the mouse visual system. Dev. Dyn. 235: 594-605.

Halder, G., Callaerts, P., and Gehring, W.J. 1995. Induction of ectopic eyes by targeted expression of the eyeless gene in Drosophila. Science 267: 1788-1792.

Hamburger, V. and Hamilton, H.L. 1992. A series of normal stages in the development of the chick embryo. Dev. Dyn. 195: 231-272.

Hammerschmidt, M., Bitgood, M.J., and McMahon, A.P. 1996. Protein kinase A is a common negative regulator of Hedgehog signaling in the vertebrate embryo. Genes \& Dev. 10: 647-658.

Hou, S.X., Zheng, Z., Chen, X., and Perrimon, N. 2002. The Jak/STAT pathway in model organisms: Emerging roles in cell movement. Dev. Cell 3: 765-778.

Incardona, J.P., Gruenberg, J., and Roelink, H. 2002. Sonic hedgehog induces the segregation of patched and smoothened in endosomes. Curr. Biol. 12: 983-995.

Ingham, P.W. and McMahon, A.P. 2001. Hedgehog signaling in animal development: Paradigms and principles. Genes \& Dev. 15: 3059-3087.

Kammandel, B., Chowdhury, K., Stoykova, A., Aparicio, S., Brenner, S., and Gruss, P. 1999. Distinct cis-essential modules direct the time-space pattern of the Pax6 gene activity. Dev. Biol. 205: 79-97.

Li, W., Ohlmeyer, J.T., Lane, M.E., and Kalderon, D. 1995. Function of protein kinase A in hedgehog signal transduction and Drosophila imaginal disc development. Cell 80: 553-562.

Litingtung, Y. and Chiang, C. 2000. Specification of ventral neuron types is mediated by an antagonistic interaction between Shh and Gli3. Nat. Neurosci. 3: 979-985.

Macdonald, R., Barth, K.A., Xu, Q., Holder, N., Mikkola, I., and Wilson, S.W. 1995. Midline signalling is required for Pax gene regulation and patterning of the eyes. Development 121: 3267-3278.

Marti, E., Takada, R., Bumcrot, D.A., Sasaki, H., and McMahon, A.P. 1995. Distribution of Sonic hedgehog peptides in the developing chick and mouse embryo. Development 121: 2537-2547.

McLaughlin, T., Hindges, R., Yates, P.A., and O'Leary, D.D. 2003. Bifunctional action of ephrin-B1 as a repellent and attractant to control bidirectional branch extension in dorsalventral retinotopic mapping. Development 130: 2407-2418.

Mui, S.H., Hindges, R., O'Leary, D.D., Lemke, G., and Bertuzzi, S. 2002. The homeodomain protein Vax2 patterns the dorsoventral and nasotemporal axes of the eye. Development 129: $797-804$.

Mui, S.H., Kim, J.W., Lemke, G., and Bertuzzi, S. 2005. Vax genes ventralize the embryonic eye. Genes \& Dev. 19: 12491259.

Pan, D. and Rubin, G.M. 1995. cAMP-dependent protein kinase and hedgehog act antagonistically in regulating decapentaplegic transcription in Drosophila imaginal discs. Cell 80: 543-552.

Parmantier, E., Lynn, B., Lawson, D., Turmaine, M., Namini,
S.S., Chakrabarti, L., McMahon, A.P., Jessen, K.R., and Mirsky, R. 1999. Schwann cell-derived Desert hedgehog controls the development of peripheral nerve sheaths. Neuron 23: 713-724.

Quiring, R., Walldorf, U., Kloter, U., and Gehring, W.J. 1994. Homology of the eyeless gene of Drosophila to the Small eye gene in mice and Aniridia in humans. Science 265: 785-789.

Rallu, M., Machold, R., Gaiano, N., Corbin, J.G., McMahon, A.P., and Fishell, G. 2002. Dorsoventral patterning is established in the telencephalon of mutants lacking both Gli3 and Hedgehog signaling. Development 129: 4963-4974.

Rawson, R.B. 2003. The SREBP pathway-Insights from Insigs and insects. Nat. Rev. Mol. Cell Biol. 4: 631-640.

Stathopoulos, A. and Levine, M. 2002. Dorsal gradient networks in the Drosophila embryo. Dev. Biol. 246: 57-67.

Strutt, D.I., Wiersdorff, V., and Mlodzik, M. 1995. Regulation of furrow progression in the Drosophila eye by cAMP-dependent protein kinase A. Nature 373: 705-709.

Syroid, D.E., Zorick, T.S., Arbet-Engels, C., Kilpatrick, T.J., Eckhart, W., and Lemke, G. 1999. A role for insulin-like growth factor-I in the regulation of Schwann cell survival. J. Neurosci. 19: 2059-2068.

Take-uchi, M., Clarke, J.D., and Wilson, S.W. 2003. Hedgehog signalling maintains the optic stalk-retinal interface through the regulation of Vax gene activity. Development 130: $955-968$.

Trousse, F., Marti, E., Gruss, P., Torres, M., and Bovolenta, P. 2001. Control of retinal ganglion cell axon growth: A new role for Sonic hedgehog. Development 128: 3927-3936.

Ungar, A.R. and Moon, R.T. 1996. Inhibition of protein kinase A phenocopies ectopic expression of hedgehog in the CNS of wild-type and cyclops mutant embryos. Dev. Biol. 178: 186191.

Wang, Y.P., Dakubo, G., Howley, P., Campsall, K.D., Mazarolle, C.J., Shiga, S.A., Lewis, P.M., McMahon, A.P., and Wallace, V.A. 2002. Development of normal retinal organization depends on Sonic hedgehog signaling from ganglion cells. Nat. Neurosci. 5: 831-832.

Watanabe, T. and Raff, M.C. 1988. Retinal astrocytes are immigrants from the optic nerve. Nature 332: 834-837.

Weimann, J.M., Zhang, Y.A., Levin, M.E., Devine, W.P., Brulet, P., and McConnell, S.K. 1999. Cortical neurons require Otx1 for the refinement of exuberant axonal projections to subcortical targets. Neuron 24: 819-831.

Xiao, C. and Ghosh, S. 2005. NF-кB, an evolutionarily conserved mediator of immune and inflammatory responses. $A d v$. Exp. Med. Biol. 560: 41-45.

Zhang, Y.A., Okada, A., Lew, C.H., and McConnell, S.K. 2002. Regulated nuclear trafficking of the homeodomain protein otx1 in cortical neurons. Mol. Cell. Neurosci. 19: 430-446. 


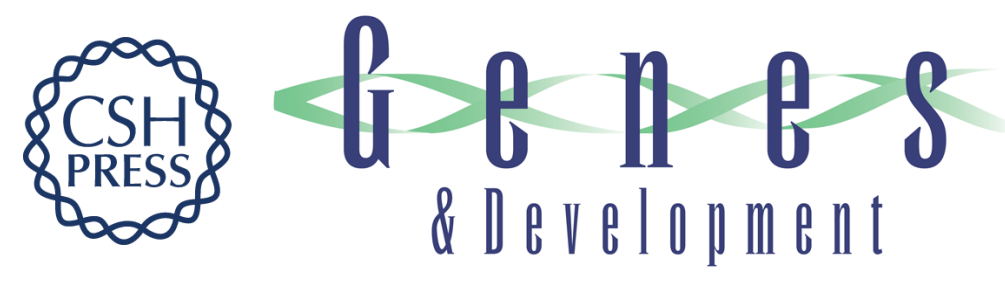

\section{Hedgehog-regulated localization of Vax2 controls eye development}

Jin Woo Kim and Greg Lemke

Genes Dev. 2006, 20:

Access the most recent version at doi:10.1101/gad.1462706

Supplemental

Material

References

This article cites 43 articles, 17 of which can be accessed free at:

http://genesdev.cshlp.org/content/20/20/2833.full.html\#ref-list-1

\section{License}

Email Alerting Service

http://genesdev.cshlp.org/content/suppl/2006/10/04/20.20.2833.DC1 right corner of the article or click here.

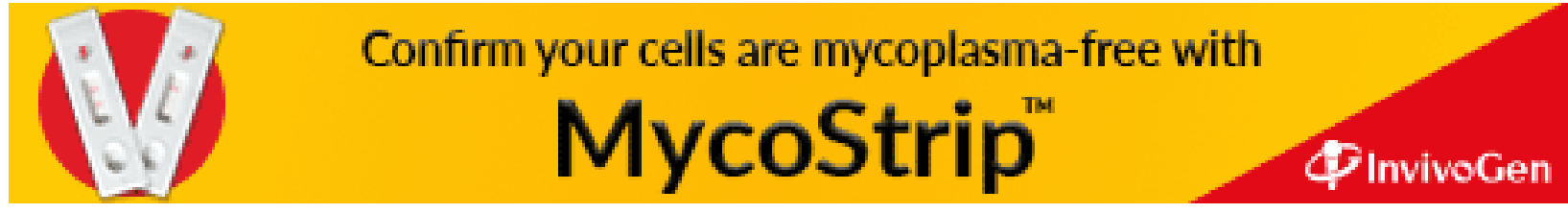

